\title{
Investigating green infrastructure as potential medium for ground heat exchangers
}

\author{
Anil Yildiz ${ }^{1,2, *}$, and Ross A. Stirling ${ }^{1,2}$ \\ ${ }^{1}$ National Green Infrastructure Facility, Newcastle upon Tyne, NE4 5TG, United Kingdom \\ ${ }^{2}$ School of Engineering, Newcastle University, Newcastle upon Tyne, NE1 7RU, United Kingdom
}

\begin{abstract}
Space heating and cooling comprises a significant portion of the overall energy consumption. Ground heat exchangers (GHE), are a sustainable alternative to conventional, non-renewably powered heating and cooling systems. Space is a scarce resource in densely urbanised areas, allocating dedicated locations to build GHE systems can result in high initial capital costs and an inflexibility in retrofitting. An alternative solution is to utilise existing, multi-benefit and resilient Sustainable Drainage Systems (SuDS) in cities. An investigation into the feasibility of utilising SuDS as sites for potential GHEs requires an understanding of their thermal and hydrological behaviour and boundary conditions. This study utilises a heavily-instrumented, vegetated lysimeter setup, exposed to atmospheric conditions, to test a pilot-scale SuDS heat exchanger. Heat rejection into the substrate of a SuDS has been simulated with the application of heat via voltage-controlled heating cables at a depth of $850 \mathrm{~mm}$ for 72 -hour durations (at three different power inputs) with 96-hours between each power input. These heat dissipation periods are reflected in measured soil temperature profiles. Volumetric water content, matric suction, soil temperature and heat flux are monitored at various locations in the lysimeter. A finite difference modelling scheme has been developed to simulate the variation in soil temperature due to heat rejection.
\end{abstract}

\section{Introduction}

Space heating and cooling constitutes a significant portion of building energy demand, contributing a large share of the total energy consumption in densely urbanised areas. The ever-increasing need to decarbonise energy supply and pursue carbon neutrality is driving the use of low- or zero-carbon technologies to heat or cool buildings. Utilisation of the ground to extract heat in winter or to reject heat in summer is a sustainable alternative to conventional systems using fossil fuels.

The main function of a ground source heat pump (GSHP) is heat extraction from, or rejection into soil by using a ground heat exchanger (GHE), usually a highdensity polyethylene (HDPE) pipe loop [1]. Vertical ground loop configurations are built in deep boreholes to exploit the stable ground temperature unaffected by the seasonal cycles of air temperature. Horizontal configurations can be used in smaller heating or cooling load applications to cut costs of drilling boreholes [2], as they are placed in shallow trenches and negate undesirable interactions with groundwater and underlying formations.

Space can be scarce in urban areas, resulting in the allocation of land to shallow GHE systems being valueengineered out of proposed developments. An alternative solution is to utilise existing (and increasingly statutory), multi-benefit Sustainable Drainage Systems (SuDS) in cities. It should be noted that the performance of shallow
GHEs can vary throughout the year due to the variation of thermal properties of the soil, i.e. thermal conductivity [3]. As the thermal properties of the soil are a function of its water content, atmospheric conditions largely dictate the efficiency of any shallow horizontal GHE $[4,5]$.

An investigation into the feasibility of utilising SuDS as sites for potential GHEs requires an understanding of their thermal and hydrological behaviour and boundary conditions. This study utilises a heavily-instrumented, vegetated lysimeter setup, exposed to natural atmospheric conditions, to test a pilot-scale SuDS heat exchanger. Heat rejection into a soil column is simulated with a heating cable connected to a variable power supply. A finite difference modelling approach has been developed to estimate temperature fluctuations in the soil due to heat rejection. The objective of this study is to evaluate to what extent the rejected heat propagates a temperature change throughout the soil profile.

\section{Materials \& methods}

\subsection{Test setup}

A soil column, as illustrated in Fig. 1, was built in an outdoor lysimeter setup located at the National Green Infrastructure Facility in Newcastle-upon-Tyne, United Kingdom. The lysimeter setup is a 2000 -mm-diameter

\footnotetext{
* Corresponding author: anil.yildiz@newcastle.ac.uk
} 
cylinder with a conical bottom, made of stainless steel. The depth at the centre is $1200 \mathrm{~mm}$, while it is $1100 \mathrm{~mm}$ at the edges. The conical bottom of the lysimeter was filled with gravel until a clear height of $1000 \mathrm{~mm}$ was reached to provide free drainage.

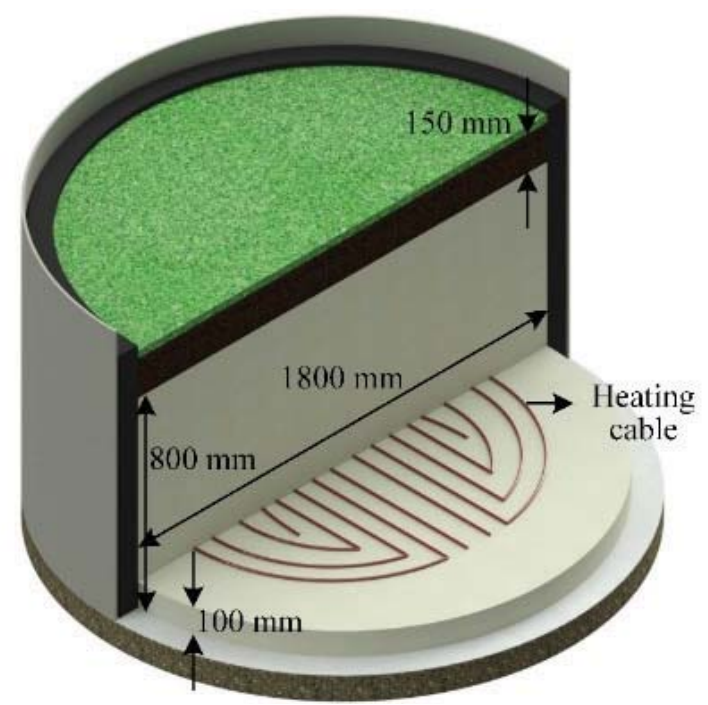

Fig. 1. Lysimeter setup used for the heat rejection tests.

A non-woven geotextile was placed above the gravel layer to prevent migration of fines. A double-walled HDPE pipe with an inner diameter of $1800 \mathrm{~mm}$ was placed in the lysimeter to insulate the soil column from the steel body and external atmospheric conditions. The final height of the soil column was $950 \mathrm{~mm}$, consisting of a sand layer of $800 \mathrm{~mm}$ height, covered with $150-\mathrm{mm}$ thick topsoil with 50-mm freeboard.

\subsection{Materials}

A fine sand, composed of $99 \%$ sand and $1 \%$ fines, was used in this study. The minimum and maximum dry densities were 1.36 and $1.64 \mathrm{Mg} / \mathrm{m}^{3}$, respectively. Specific gravity was determined as 2.68. Detailed information on the sand used in this study can be found in [6].

Topsoil used in this study is a high fertility and organic rich substrate, certified to BS3882:2015 standards. It contains $3.3 \%$ gravel, $86.3 \%$ sand, and $10.4 \%$ fines. Organic matter, determined by loss-on-ignition, was $3.4 \%$, and carbon:nitrogen ratio was 12:1 [7].

\subsection{Preparation of soil column}

A target relative density and initial water content of the sand layer was chosen as $35 \%$ and $16 \%$, respectively. The in-situ water content of the sand varied between 6 and $7 \%$, and batches of moist sand was mixed with water in a cement mixer to reach the target water content. Approximately $428 \mathrm{~kg}$ of sand was placed in the pipe for every 100-mm-high sand layer, and compaction was performed using a $6 \mathrm{~kg}$ hammer until the desired height was reached. Core-cutter density measurements provided an average bulk density of $1.67 \mathrm{Mg} / \mathrm{m}^{3}$ with a water content of $16.6 \%$ for the $800-\mathrm{mm}$ high sand column. A 150 -mm thick topsoil layer was placed above the sand layer. The total mass of the topsoil used was $460 \mathrm{~kg}$, which gives an overall bulk density of $1.20 \mathrm{Mg} / \mathrm{m}^{3}$. Topsoil was sown with winter grazing ryegrass seeds (Secale cereale). Figure 2 shows a QR code to access a detailed time lapse video of how the soil column was built in the lysimeter [8].

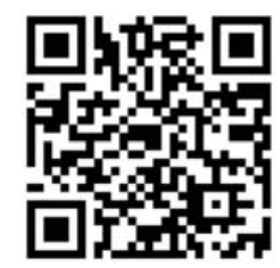

Fig. 2. QR code to visualise a time lapse video of commissioning the lysimeter setup [8]

\subsection{Heat rejection tests}

Two 10-m long heating cables (BioGreen HK 10.0) were laid to form a circle with an area of $2 \mathrm{~m}^{2}$ (See Fig. 1) at $850 \mathrm{~mm}$ below the surface. Cables were connected in parallel to a variable power supply located in the laboratory. The resistance of each cable was measured as $540 \Omega$, while the equivalent resistance at the connection terminal to the power supply was $272.1 \Omega$. Three heat rejection tests were performed, and the details are given in Table 1. Each test lasted 72 hours, with 96 hours in between. First test was performed by applying $165.6 \mathrm{~V}$, so that each cable had $50 \mathrm{~W}$ power, acting as a heat source of $25 \mathrm{~W} / \mathrm{m}^{2}$. Second and third tests were conducted at power inputs of $30 \mathrm{~W}$ and $10 \mathrm{~W}$ to yield heat inputs of 15 $\mathrm{W} / \mathrm{m}^{2}$ and $5 \mathrm{~W} / \mathrm{m}^{2}$, respectively.

Table 1. Details of the heat rejection tests

\begin{tabular}{lrrrr}
\hline Test\# & Start & End & $\begin{array}{r}\text { Power } \\
{[\mathbf{W}]}\end{array}$ & $\begin{array}{r}\text { Voltage } \\
{[\mathbf{V}]}\end{array}$ \\
\hline $\mathbf{1}$ & 19.07 .2019 & 22.07 .2019 & 50 & 165.6 \\
& $08: 30$ UTC & $08: 30$ UTC & & \\
$\mathbf{2}$ & 26.07 .2019 & 29.07 .2019 & 30 & 128.3 \\
& $08: 30$ UTC & $08: 30$ UTC & & \\
$\mathbf{3}$ & 02.08 .2019 & 05.08 .2019 & 10 & 74.1 \\
\hline
\end{tabular}

\subsection{Instrumentation}

\subsubsection{Measurement of hydrological parameters}

Volumetric water content and matric suction were monitored with 5TE and MPS6 from Meter Group, respectively. Both sensors work on estimating the corresponding parameters from measurements of dielectric permittivity. Two sensors of each were placed $200 \mathrm{~mm}$ away from the central axis of the soil column at $100 \mathrm{~mm}$ below the surface in the topsoil, and at every 100 $\mathrm{mm}$ starting from $250 \mathrm{~mm}$ until $750 \mathrm{~mm}$ in the sand layer. 
A total of 28 sensors were connected via SDI-12 protocol to a data logger, Delta-T Devices GP2. Measurements were taken every 60 seconds. A spatial average value of matric suction and volumetric water content is obtained by taking the mean of readings from both sensors at each depth, and temporal average values are calculated every 15 minutes.

\subsubsection{Measurement of thermal parameters}

Soil temperature and heat flux are the main thermal parameters measured in the soil column in this study. Each sensor used to monitor the hydrological parameters is able to provide soil temperature values. Apart from these sensors, a soil temperature profiler, Hukseflux STP01, was placed $50 \mathrm{~mm}$ below the surface, providing readings at $70,100,150,250$, and $550 \mathrm{~mm}$. An averaging soil thermocouple probe at 20 and $60 \mathrm{~mm}$, Campbell Scientific - TCAV, was placed in the topsoil to estimate an average temperature at $40 \mathrm{~mm}$ below the surface. Soil temperature around the heating cable was monitored using thermistors, Campbell Scientific - 107, at 800, 850 and $900 \mathrm{~mm}$. Heat flux was measured below the heating cable at $940 \mathrm{~mm}$, and below the surface at $80 \mathrm{~mm}$ with HFP01 sensors from Hukseflux.

\section{Field monitoring}

Monitoring results presented herein cover a period between 18.07.2019 00:00 UTC and 08.08.2019 00:00 UTC, and are shared in Open Access form via an API by the NGIF (https://api.ngif.urbanobservatory.ac.uk).

Figure $3 \mathrm{a}$ shows the variation of volumetric water content with depth during the period of heat rejection tests. Only the shallowest measurement in the topsoil layer, at $100 \mathrm{~mm}$, showed a significant change during the period of measurement. Measurements in the sand layer, from $450 \mathrm{~mm}$ to $750 \mathrm{~mm}$, decreased in general. Change in the volumetric water content of the sand was greatest in the deeper layers, whereas shallow depths experienced less change. Mean reduction at depths 250 and $350 \mathrm{~mm}$ was $0.08 \%$, whereas the measurements at 550,650 and $750 \mathrm{~mm}$ showed a mean decrease of $3.00 \%$.

The total amount of water drained from the bottom of the lysimeter during the field monitoring campaign was recorded as $0.675 \mathrm{~L}$. However, a $3.00 \%$ change in the volumetric water content of a $100-\mathrm{mm}$ thick layer in the lysimeter corresponds to a loss of $7.64 \mathrm{~L}$ of water. Therefore, as the hydrological regime of the shallow layers of sand did not vary significantly, and most changes occurred at the deeper layers, it can be speculated that the reduction in the water content is due to the heat rejection. This can be a result of the moisture migration due to diffusion under temperature gradient [9]. A reduction in water content at the same suction due to increased temperature was evident in laboratory experiments on lou soil and sandy loess [10].

Figure $3 b$ illustrates the effects of heat rejection on soil temperature and how the rejected heat propagates through the soil column. Heat rejection increased the soil temperature, especially at deeper layers, i.e. from 450 to
$750 \mathrm{~mm}$, and the effect of rejected heat decreased with increasing distance from the heat source. Measurements at $750 \mathrm{~mm}$ below the surface showed that the change in soil temperature $(\Delta T)$, expressed as the difference between the values before the heat rejection and maximum temperature obtained during the test, was $7.9^{\circ}$, $3.6^{\circ}$ and $1.5^{\circ}$ during Tests 1,2 and 3, respectively. Increased soil temperature was evident during the operation of a functional ground source heat pump for space cooling [11]. Furthermore, results of the monitoring also show that the fluctuation in the soil temperature at depths more than $350 \mathrm{~mm}$ were due to the heat rejection, while the shallow layers experienced the diurnal variation of air temperature.
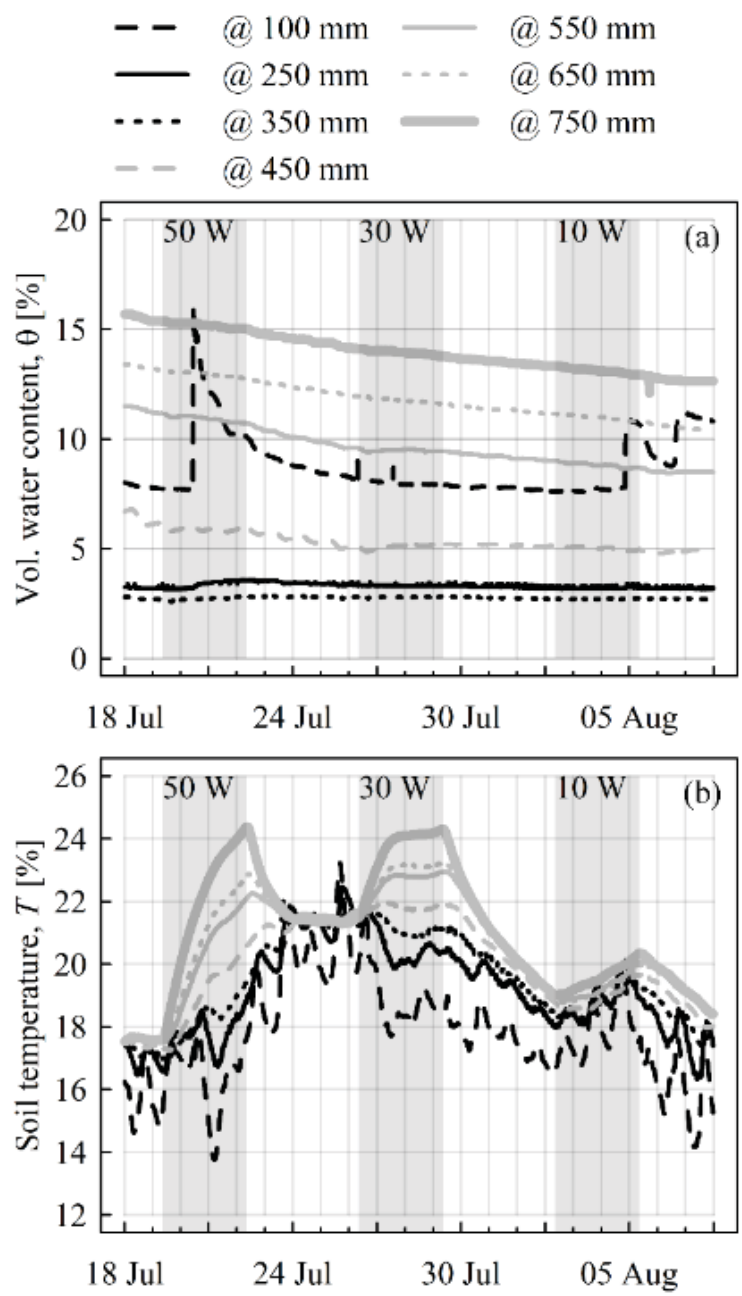

Fig. 3. Variation of (a) volumetric water content and (b) soil temperature during the period of monitoring. Grey marked areas show the heat rejection tests.

\section{Numerical modelling}

\subsection{Modelling approach}

Variation in soil temperature with depth and in time was modelled by using Fourier's law of heat conduction in one dimension and conservation of energy, as shown in Eq. 1. 


$$
\frac{\partial T}{\partial t}=\alpha\left(\frac{\partial^{2} T}{\partial^{2} z}\right)
$$

This partial differential equation, in which $\alpha$ represents the thermal diffusivity, was solved with an explicit finite difference method using the information from the previous time step. Figure 4 shows the discretisation of the soil column for estimating soil temperature.

\begin{tabular}{|c|c|c|c|c|}
\hline \multicolumn{3}{|c|}{$\mathrm{j}=\mathrm{t}_{0}$} & \multicolumn{2}{|c|}{$\mathrm{j}+1=\mathrm{t}_{0}+\Delta \mathrm{t}$} \\
\hline 50 & & $\mathrm{~T}_{b c}{ }^{\mathrm{j}}$ & & $\mathrm{T}_{b c} l^{\mathrm{j}+1}$ \\
\hline 150 & 1 & $\mathrm{~T}_{1}{ }^{\mathrm{j}}$ & 1 & $\mathrm{~T}_{\mathrm{I}}^{\mathrm{j}+1}$ \\
\hline 250 & 2 & $\mathrm{~T}_{2}^{\mathrm{j}}$ & 2 & $\mathrm{~T}_{2}^{\mathrm{j}+1}$ \\
\hline 350 & 3 & $\mathrm{~T}_{3}^{\mathrm{j}}$ & 3 & $\mathrm{~T}_{3}{ }^{\mathrm{j}+1}$ \\
\hline 450 & 4 & $\mathrm{~T}_{4}^{\mathrm{j}}$ & 4 & $\mathrm{~T}_{4}{ }^{\mathrm{j}+1}$ \\
\hline 550 & 5 & $\mathrm{~T}_{5}^{\mathrm{j}}$ & 5 & $\mathrm{~T}_{5}^{\mathrm{j}+1}$ \\
\hline 650 & 6 & $\mathrm{~T}_{6}^{\mathrm{j}}$ & 6 & $\mathrm{~T}_{6}{ }^{\mathrm{j}+1}$ \\
\hline 750 & 7 & $T_{f}^{j}$ & 7 & $\mathrm{~T}_{7}^{\mathrm{j}+1}$ \\
\hline 850 & & $\mathrm{~T}_{b c 2^{\mathrm{j}}}$ & & $\mathrm{T}_{h c 2^{j+1}}$ \\
\hline
\end{tabular}

Fig. 4. Discretisation of the soil column for numerical modelling.

The upper boundary was chosen as $50 \mathrm{~mm}$ in order to have equal node spacing of $100 \mathrm{~mm}$. As there were no point measurements at $50 \mathrm{~mm}$, the average temperature from the measurements at 20,60 , and $70 \mathrm{~mm}$ was taken as the boundary condition $(b c 1)$. The lower boundary $(b c 2)$ was chosen as the heating cable at $850 \mathrm{~mm}$. Heat rejection is modelled by defining a heat flux $\left(q_{b c 2}\right)$ at the lower boundary. As heat flux was measured at $940 \mathrm{~mm}$, rather than the depth at which the boundary condition was defined, the energy stored in layer between the heat flux plate and the corresponding boundary $\left(Q_{\text {stored }}\right)$ was calculated using Eq. 2 [9]. $Q_{\text {stored }}$ is a function of the change of temperature at each time step, the distance between the boundary and the heat flux plate $(z)$, the volumetric heat capacity $(C)$ and the time step $(\Delta t)$. The heat flux at the boundary was calculated by adding the measured heat flux to $Q_{\text {stored }}$.

$$
Q_{\text {stored }}=\frac{\left(T^{j+1}-T^{j}\right) * Z * C^{j}}{\Delta t}
$$

Temperature values at the time step $j+1=t_{0}+\Delta t$ at $b c 2$ were estimated using Eq. 3, which requires a node outside the domain for calculation. Therefore, the soil temperature at $900 \mathrm{~mm}\left(T_{900}\right)$ was taken as the reference point to estimate the temperature at $b c 2$ in time.

$$
T_{b c 2}^{j+1}=T_{b c 2}^{j}+\alpha_{b c 2}{ }^{j} \frac{T_{T 900}^{j}-T_{b c 2}^{j}}{\Delta z^{2}} \Delta t+\frac{q_{b c 2}^{j} \Delta t}{C_{b c 2}^{j} \Delta z}
$$

Temperature at time $j+1=t_{0}+\Delta t$ for points from 1 to 7, shown in Fig. 4, can be calculated using the values at time $j=t_{0}$ as follows:

$$
T_{i}^{j+1}=T_{i}^{j}+\alpha^{j} \frac{T_{i+1}^{j}-2 T_{i}^{j}+T_{i-1}^{j}}{\Delta z^{2}} \Delta t
$$

A time step, $\Delta t$, of 15 minutes and a vertical distance, $\Delta z$, of $100 \mathrm{~mm}$ were chosen in order to satisfy the CourantFriedrichs-Levy (CFL) criteria of stability, as shown in Eq. 5.

$$
\alpha \frac{\Delta t}{\Delta z^{2}} \leq 0.5
$$

An algorithm to perform the model calculations was written in R 3.5.2 [13]. Heat flux at $b c 2$ is calculated using Eq. 2, and the initial conditions are defined at time step $t_{0}$. At each time step, thermal properties are estimated based on the volumetric water content measurements. The temperature values at $b c 2$ are estimated by using Eq. 3 for the time step $t_{0}+\Delta t$. Afterwards, modelled temperatures for nodes between 1 to 7 are obtained by using Eq. 5 .

\subsection{Model parameters}

Thermal properties of the soils used in the model are the thermal diffusivity, $\alpha$ in $\mathrm{mm}^{2} / \mathrm{s}$, and the volumetric heat capacity, $C$ in $\mathrm{Wh} / \mathrm{m}^{3} \mathrm{~K}$. As $b c l$ was chosen as measured temperature, the only parameter required for the topsoil is $\alpha$, whereas both $\alpha$ and $C$ are needed for the sand, as the calculation of heat flux at $b c 2$ requires values of $C$, as well.

A saturated sample of the sand and topsoil at dry densities corresponding to the average values measured in the sand column were prepared in a $250-\mathrm{ml}$ mould and left to evaporate on top of a high precision balance, while measuring the thermal properties with a KD2 Pro Thermal Properties Analyser. As the change in the mass is due to evaporation only and no volume change was observed, gravimetric and volumetric water content values can be calculated. Figure 5 shows the change in $C$ and $\alpha$ in time with respect to volumetric water content $(\theta)$, as well as the fitted curves to the measured data.

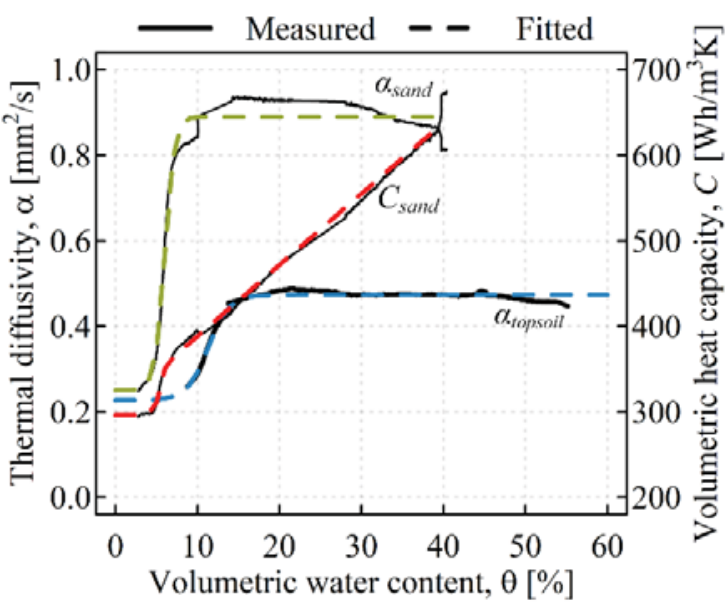

Fig. 5: Thermal parameters used in modelling. Solid lines show the measured data, whereas the dotted lines are the fitted curves. 
A basic sigmoid curve was fitted to measured $\alpha$ values, Eq. 6, whereas a modified sigmoid curve is used for $C$, Eq. 7. A non-linear least square method is employed to fit the curves defined to the measured data.

$$
\begin{aligned}
& \alpha=\frac{a}{1+e^{-b(\theta-c)}}+d \\
& C=\frac{a+k(\theta-c)}{1+e^{-b(\theta-c)}}+d
\end{aligned}
$$

Table 2 shows the fitting parameters, as well as residual standard error for each fit. The algorithm used in the modelling calculated either $\alpha$ or $C$ value at each step based on the volumetric water content measurement. In case a measurement at the depth corresponding to a node is not present, i.e. 150 and $850 \mathrm{~mm}$, the volumetric water content from the closest point is used.

Table 2. Fitting parameters and residual standard error for thermal diffusivity, $\alpha$, and volumetric heat capacity, $C$.

\begin{tabular}{lrrr}
\hline & \multicolumn{2}{c}{$\boldsymbol{\alpha}$} & \multicolumn{1}{c}{$\boldsymbol{C}$} \\
& Topsoil & Sand & Topsoil \\
\hline $\boldsymbol{a}$ & 0.25 & 0.64 & 52.7 \\
$\boldsymbol{b}$ & 0.78 & 1.72 & 3.24 \\
$\boldsymbol{c}$ & 11.3 & 6.01 & 5.27 \\
$\boldsymbol{d}$ & 0.23 & 0.25 & 296.4 \\
$\boldsymbol{k}$ & - & - & 8.32 \\
Res. stand. error & 0.008 & 0.028 & 6.739 \\
\hline
\end{tabular}
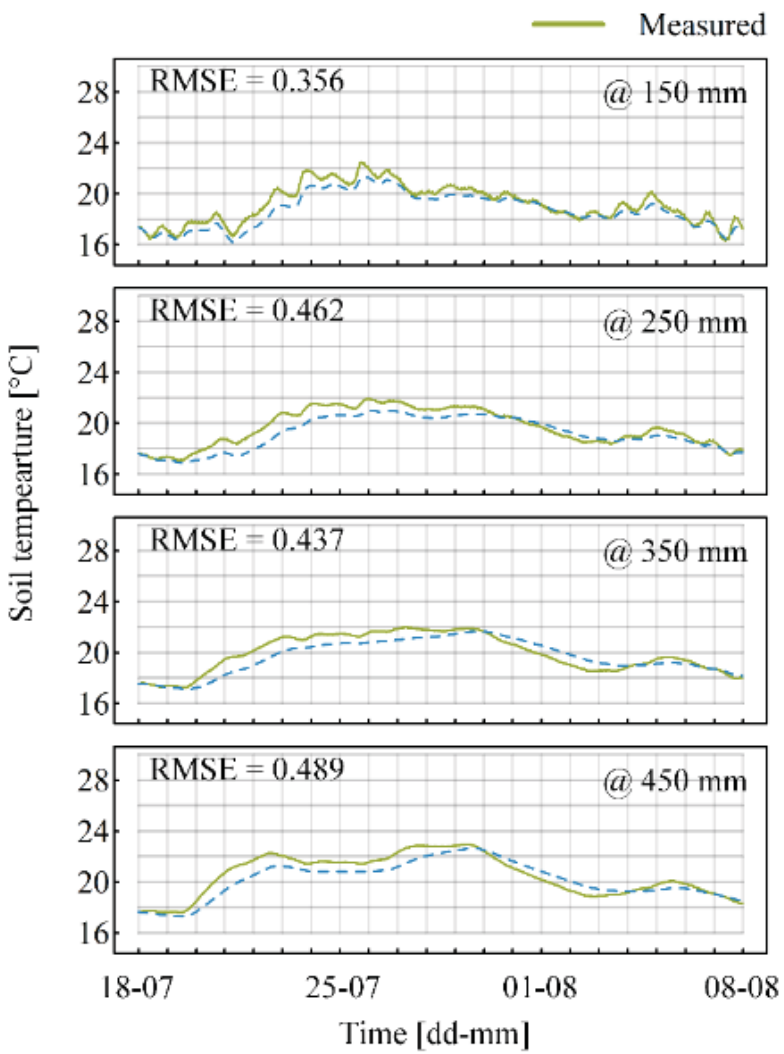

\subsection{Estimation of soil temperature}

Soil temperature at nodes from 1 to 7 , as well as at $b c 2$, are estimated every 15 minutes from 18.07.2019 00:00 UTC until 08.08.2019 00:00 UTC using the modelling approach described.

The model developed in this study is able to capture the variation in the soil temperature of deep layers, i.e. deeper than $450 \mathrm{~mm}$, due to heat rejection, as well as the diurnal variation in the shallow layers (See Fig. 6). Magnitudes of the temperature are tended to be underestimated for layers up to $550 \mathrm{~mm}$, whereas a slight overestimation can be observed in the simulations of layers deeper than $650 \mathrm{~mm}$.

Figure 6 also shows the root mean square error (RMSE) of simulations according to depth. Lower values of RMSE, higher estimation capability of the model, are found for deeper layers. This may be a result of the specified boundary conditions. While the upper boundary condition was a temperature value averaged from two sensors at different locations, the lower boundary condition was defined as a heat flux measurement. The decreasing difference between measured and simulated soil temperatures with increasing depth was also found in a similar finite difference model [14].

The first node in this model is at the interface between the topsoil and sand. Simulation results presented herein use the thermal properties and volumetric water content of the topsoil, i.e. as measured at $100 \mathrm{~mm}$. A second simulation at $150 \mathrm{~mm}$ is performed using $\alpha$ of the sand layer, and the volumetric water content from the
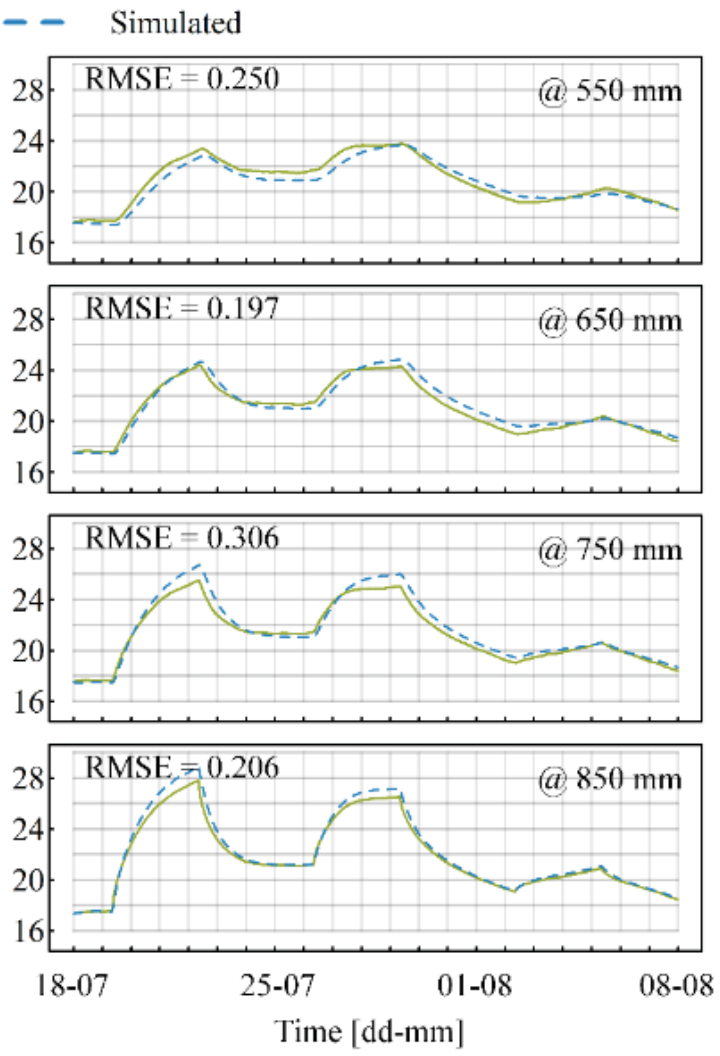

Fig. 6. Comparison of measured and simulated soil temperatures during heat rejection tests. Root mean square error (RMSE) values are also provided. 
measurements at $250 \mathrm{~mm}$. An RMSE of 0.362 was found for this simulation, compared to 0.356 (See Fig. 6), suggesting that the choice of thermal parameters for the model do not significantly affect the model outcome for the interface. Simulations using an average value of thermal diffusivity are shown to produce results similar to simulations using a non-homogenous profile [15].

\section{Conclusions}

This paper presents the results of an experimental campaign and a numerical model to investigate heat rejection into the substrate of a pilot-scale SuDS. Heat rejection in the experiments was provided via a heating cable with variable power input, allowing a range of heat loads to be applied. A finite-difference model has been developed in order to simulate fluctuations in soil temperature. Data derived from laboratory testing and a densely instrumented SuDS enabled model validation. A reduction in water content in the vicinity of the heat source was observed, which can be attributed to the heat rejection. The numerical model is shown to be capable of simulating the observed, transient soil temperatures at various depths. The proposed model will be used to further investigate both heat rejection (e.g. variable building operative loads) and SuDS (e.g. prolonged drought, short- and long-term inundation) scenarios.

This study was funded by the EPSRC grant PLEXUS - Priming Laboratory EXperiments on infrastructure and Urban Systems (EP/R013535/1) and hosted by the UKCRIC National Green Infrastructure Facility (EP/R010102/1). The authors are thankful to technicians Gareth Wear, Michael Finley and Kevin Stott for the help during the setup of the experiment, and to Assoc Prof A. Ufuk Sahin and Dr Peter Helm for fruitful discussions about the modelling framework.

\section{References}

1. I. Sarbu, C. Sebarchievici General review of groundsource heat pump systems for heating and cooling of buildings Energy and Build. 70441 - 454 (2014)

2. R. Wu, J.M. Tinjum, W.J. Likos Coupled Thermal Conductivity Dryout Curve and Soil-Water Characteristic Curve in Modeling of Shallow Horizontal Geothermal Ground Loops Geotech Geol Eng. $33193-205$ (2015)

3. R.B. Simms, S.R. Haslam, J.R. Craig Impact of soil heterogeneity on the functioning of horizontal ground heat exchangers Geothermics 5035 - 43 (2014)

4. F. Tang H. Nowamooz Outlet temperatures of a slinky-type Horizontal Ground Heat Exchanger with the atmosphere-soil interaction Ren. Energy 146705 -718 (2020)

5. G. Go, S. Lee, N.V. Nikhil, S. Yoon A new performance evaluation algorithm for horizontal GCHPs (ground coupled heat pump systems) that considers rainfall infiltration Energy 83766 - 777 (2015)

6. A. Yildiz, R. Stirling, S. Glendinning Monitoring of thermo-hydrological behaviour in Green
Infrastructure E-UNSAT 2020 4th Eur. Conf. on Unsat. Soils (2020)

7. https://www.green-tech.co.uk/specialist-top-soils/topsoil/green-tree-topsoil

8. https://www.youtube.com/watch? $\mathrm{v}=\mathrm{e} 4 \mathrm{RBqE} 6 \mathrm{~g} \mathrm{Jg} \& \mathrm{t}$

9. Y. Liu, G. Huang, J. Lu, X. Yang, C. Zhuang, J. Qin A novel 2-D ring-tubes model and numerical investigation of heat and moisture transfer around helix ground heat exchanger Geothermics 85101789 (2020)

10. H. Gao, M. Shao Effects of temperature changes on soil hydraulic properties Soil \& Till. Res. 153145 154 (2015)

11. M. Kim, S. Lee, S. Yoon, G. Go Thermal performance evaluation and parametric study of a horizontal ground heat exchanger Geothermics $60134-143$ (2016)

12. https://s.campbellsci.com/documents/eu/manuals/tca V.pdf

13. $\mathrm{R}$ Core Team $\mathrm{R}$ : A language and environment for statistical computing (2017)

14. M. Chalhoub, M. Bernier, Y. Coquet, M. Philippe A simple heat and moisture transfer model to predict ground temperature for shallow ground heat exchangers Ren. Energy 103295 - 307 (2017)

15. H. Nowamooz, S. Nikoosokhan, J. Lin, C. Chazallon Finite difference modeling of heat distribution in multilayer soils with time-spatial hydrothermal properties Ren. Energy 767 - 15 (2015) 